\title{
Design and analysis of elevator wire ropes
}

\author{
Anil Babu Seelam, Mohammad Saif Jawed, and Sachidananda Hassan Krishanmurthy ${ }^{*}$ (D) \\ School of Engineering and IT, Manipal Academy of Higher Education, Dubai 345050, UAE
}

Received: 26 May 2021 / Accepted: 30 August 2021

\begin{abstract}
In this research paper design and analysis of wire ropes used in elevator have been presented. The main objective of this study is to find the best practices on handling wire ropes for safety and to reduce the downtime of elevators due to wire rope failures. Design calculations have been done to calculate the apt dimensions and design is constructed on Auto Desk inventor software and the analysis have been performed using Ansys. Two configurations of the wire ropes have been studied and from this result it can be concluded that the design of wire rope is possible to relieve mechanical handling and to improve the design of wire ropes making it more durable by possible inclusion of new materials which in turn increases the efficiency and life of wire ropes without compromising safety.
\end{abstract}

Keywords: Mechanical engineering / safety research / numerical analysis / transportation

\section{Introduction}

Wire ropes are used for lifting and hoisting in cranes and elevators. They are commonly used for hoisting in elevator cars. The different types of wire ropes have been designed and tested for various applications to carry a tensile load. So, these types of wire are tested for both static and fatigue loading and these loads are transmitted through a flexible member $[1,2]$. Wire ropes are structural elements commonly used in industries and civil engineering domain. They consist of several steel wires twisted on the central core to improve the axial strength, stiffness and bending flexibility which in turn increases the mechanical properties. Wire ropes are usually made of many structures and they can fulfil their task of carrying tensile load without breaking [3]. Wire ropes are usually subjected to varying axial tensile loads or torsional moments resulting in unstable performances [4]. So, in this context wire ropes are usually analysed for stress and strain to study its mechanical strength [5] and hence research on this wire ropes are significant.

Wire ropes are composed of several twisted wires in a specific arrangement strands and then wound in a helical pattern around the central core. Imrak and Erdonmez [6] have studied new techniques in modelling of wire ropes. Initially they developed a modelling of wire rope using simple straight strand and they adapted this procedure for whole wire rope structure using double helical geometry.

\footnotetext{
* e-mail: sachidananda@manipaldubai.com
}

They concluded this modelling procedure is easier and effective. Their results showed good agreement with other available literature and is considered simpler.

Fatigue performance in case of wire ropes depends on crack propagation which occurs in the internal and external cross sections of the wire rope and its ability to withstand abrasion and plasticity after long use [7]. So, the design of rope is carefully selected and constructed, and the lubricants are used to reduce the localized friction of individual wires in the strand. Kim et al. [8] have studied effect of wire rope diameter and tensile stress to study the life of wire rope. They considered five wire rope of $8 \mathrm{~mm}$ and $10 \mathrm{~mm}$ wire diameter and applied a constant tensile load and observed bending fatigue strength for different cycles. They concluded that the fracture surface area was larger in case of larger wire diameter and these data can be used to study the structural integrity in case of wire rope. The applications and the method of manufacturing wires are different for different equipment and it depends upon surface finish, texture lay, whirling grade, stress capacity, tolerance etc. [9]. So, it has become quite normal to expect wire rope construction from varying manufacturers, it becomes necessary to perform some mandatory tests before to determine various responses and reactions to various loading conditions. Barkany et al. [10] have studied nondestructive evaluation and discard criteria of wire rope giving importance to internal damage. They used the electromagnetic non-destructive and other methods to study the broken wire used in crane ropes and hoist ropes. They recommended to conduct magnetic test every year to check the failure criteria of wire rope. Sukhorukov et al. [11] 
have studied electromagnetic non-destructive inspection to inspect the wire ropes commonly used in oil and gas and mining industries. They concluded that electromagnetic non-destructive methods can be used to meet the challenges to study the failure and discard criteria. Rostami et al. [12] have studied the condition monitoring of a steel wire rope which was broken due to corrosive and fatigue used in case of hoisting elevator. They used finite element analysis to study wave propagation in wire ropes. They concluded by recording those wave propagations to analyse the wire rope. Zhang et al. [13] have studied electromagnetic techniques to study the wire rope. They designed a sensor to detect the broken wire using magnetic flux leakage method. They concluded that the designed sensor was optimized, and the performance of magnetic concentration have been analysed using Finite element method.

Wire ropes that operate on sheaves are subjected to various stresses due to which possible failures may take place. The life of the wire rope tends to decrease when it is subjected to increasing axial load and decreasing sheave bend radii. At the same time, the bending of the ropes on elevator pulleys will increase the cross section of the wire rope at the outer cross section whereas the inner most wires tend to shorten and is considered to be the main cause of damage and wear in the elevator operation units $[14,15]$. In this context Shi et al. [14] have studied a 3D model using finite element method considering $6+1$ wire rope strand to investigate the traction between wire and sheave. They studied the tensile distribution in the wire. They concluded that contact wrap angle is critical in traction capability calculations. Nabijoe and Hobbs [15] have studied the frictional behaviour in case of heavily loaded wire ropes bent over sheaves considering different diameters. They concluded that the reduction in the ratio of D:d (diameter of the sheave and diameter of wire rope) exhibit larger travel distance of the individual wires and the multiple strands of the unit leading to increasing wear and in turn reduction in the life of the rope. Hence, careful consideration of the wire rope selection plays an important role for various types of applications. Vogel [16] have studied the endurance and the lifetime of the wire rope over the sheave. He studied the influence of rope considering the rope length and size factors in case of lift application operations. They concluded the influence of rope length and size factors on the life of the wire rope. Xi et al. [17] have studied the wire rope failures using Non-destructive testing based on magnetic and infrared information. They considered the broken wire for their testing, and they concluded that using this method it is possible to estimate the residual lifetime of the wire rope. From this literature review it is observed that researchers have studied wire ropes which are commonly used in lifting and hoisting in case of cranes and elevators. Most of the researchers have designed wire ropes to study tensile loading considering both static and fatigue loading apart, stiffness and bending flexibility to improve the performance (Mechanical strength) of wire rope. Also, some researchers have designed and studied the strand in case of wire ropes to study its ability to withstand abrasion and plasticity to improve the life of wire ropes. In this research paper wire ropes have been studied for safety purposes to reduce the downtime of elevators and the analysis have been performed using ANSYS considering two configurations of wire ropes by introducing new materials to increase the efficiency and life of wire ropes.

\section{Methodology}

The base model of the wire rope is Autodesk inventor and the analysis are performed using Ansys software. Two configurations of wire ropes have been designed and their diameters is selected as $22 \mathrm{~mm}$ and $24 \mathrm{~mm}$ and the corresponding model is as shown in Figure 1. The corresponding dimension and other properties of the wire rope is as shown in Table 1 . The maximum load considered is $45 \mathrm{kN}$ and the wire rope diameter selected is $22 \mathrm{~mm}$. The wire rope configuration selected for the analysis is as shown in Table 2 and Table 3.

The efficiency of wire rope is calculated using the following equation.

$$
\eta_{s}=\left(\eta_{r}\right)^{i} \eta_{f}=\left(\eta_{r}\right)^{i}\left(\frac{1}{n}\right)\left(\frac{1-\left(\eta_{r}\right)^{i}}{1-\eta_{r}}\right)
$$

where $\eta_{f}$ is efficiency of pulley block, $\eta_{r}$ is efficiency of one pulley block $=0.96$ to $0.98, i$ is the number of pulleys $=6$ and $n$ is the number of ropes $=5$.

Diameter of individual wires of the wire rope $\left(d_{w}\right)$ is calculated using

$$
d_{w}=\frac{d}{1.5 \times \sqrt{i}}
$$

The minimum rope diameter is determined using the following formula:

$$
d=C \times \frac{\sqrt{F}}{\sqrt{\eta_{s}}}
$$

where $d(\mathrm{~mm})$ is Minimum Rope Diameter, $C$ is Strength factor, $F$ is Calculated traction Force, $\eta_{s}$ is Efficiency of wire rope.

The Diameter ratio (For Car Sheaves, Counterweight Sheaves and Drive Sheaves):

$$
x=\frac{D_{p}(\text { Diameter of Pulley })}{\left.\mathrm{D}_{\mathrm{r}} \text { (Diameter of Rope }\right)} .
$$

The Friction coefficient that is experienced by the rope $\left(m_{y}\right)$

$$
m_{y}=\frac{0.1}{\left(\frac{1+v}{10}\right)} \text { where } v=\operatorname{ropespeed}(\mathrm{m} / \mathrm{s}) .
$$

The Rope Friction factor $(f)$ during operation situation is calculated using

$$
f=m_{y} 4\left(\frac{\frac{1-\sin \beta}{2}}{\pi-\beta-\sin \beta}\right)
$$



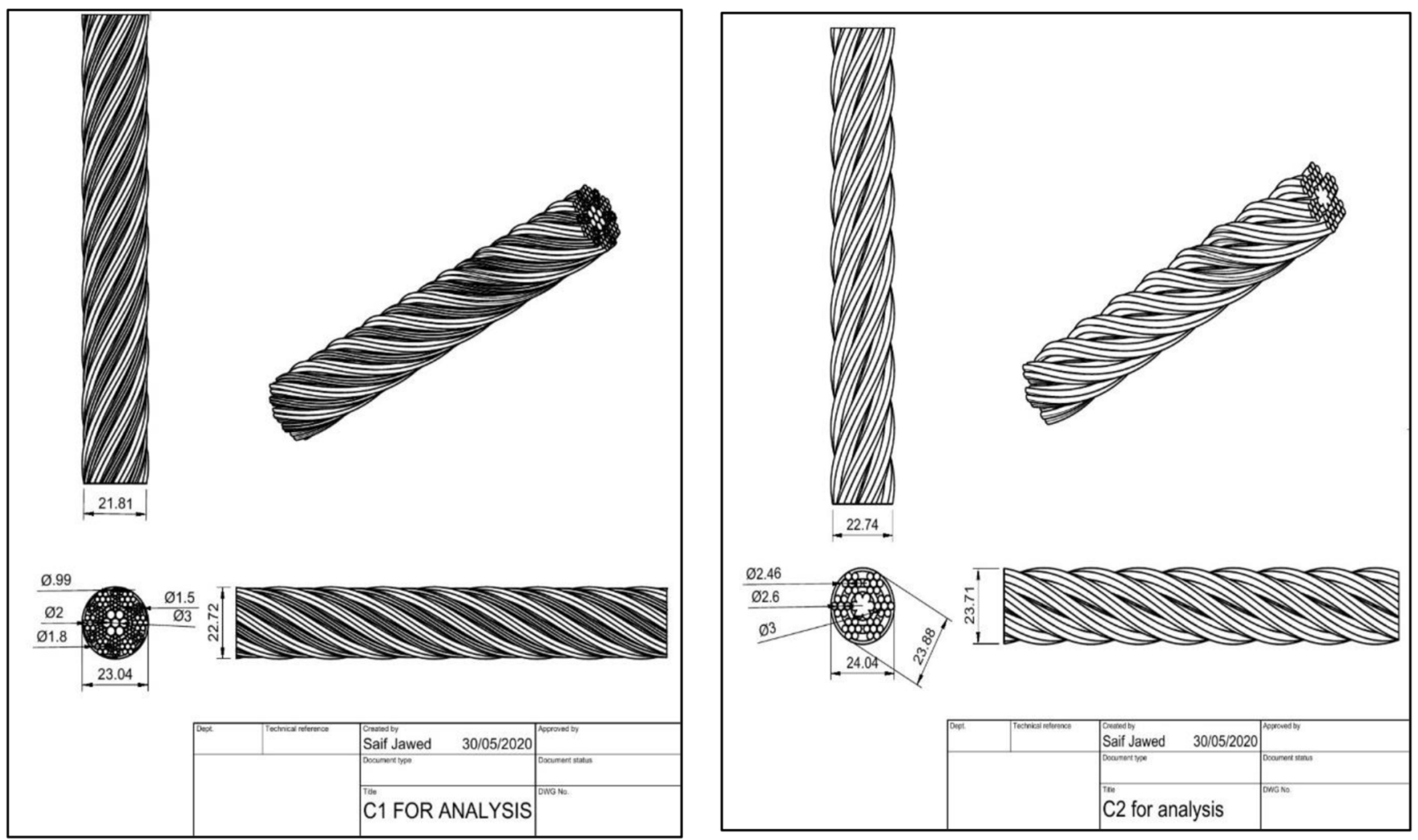

Fig. 1. Wire rope design configuration 1 and 2 .

Table 1. Design selection and characteristics.

\begin{tabular}{lll}
\hline $\begin{array}{l}\text { Diameter of } \\
\text { the rope }(\mathrm{mm})\end{array}$ & $\begin{array}{l}\text { Approximate } \\
\text { weight } \mathrm{N} / \mathrm{m}\end{array}$ & $\begin{array}{l}\text { Nominal breaking tensile } \\
\text { strength of rope }\left(\mathrm{N} / \mathrm{mm}^{2}\right)\end{array}$ \\
\hline 22 & 17.75 & 241.24 \\
24 & 20.594 & 278.51 \\
\hline
\end{tabular}

Table 2. Wire rope configuration 1 material compositional specifications.

\begin{tabular}{|c|c|}
\hline \multicolumn{2}{|c|}{$\begin{array}{l}\text { CONFIGURATION } 1 \text { - Material Compositional } \\
\text { Specifications }\end{array}$} \\
\hline Primary Strand & Stainless Steel AISI 440C $(1.20 \% \mathrm{C})$ \\
\hline Secondary Strand & Stainless Steel AISI $440 \mathrm{C}(1.20 \% \mathrm{C})$ \\
\hline Tertiary Strand & Stainless Steel AISI $440 \mathrm{C}(1.20 \% \mathrm{C})$ \\
\hline Central Core Wires & Stainless Steel AISI 440C $(1.20 \% \mathrm{C})$ \\
\hline Central Core Core & Carbon Steel AISI 410 \\
\hline
\end{tabular}

where $m_{y}=$ friction coefficient ( 0.5 for operation situation and 1 for braking situation and stand still situation), beta $(\beta)=$ undercut angle $=105^{\circ}$.

The Rope friction factor during Emergency braking situation is given as

$$
f=m_{y} 4\left(\frac{\frac{1-\sin (1.83)}{2}}{\pi-1.83-\sin (1.83)}\right) .
$$

Table 3. Wire rope configuration 2 material compositional specifications.

CONFIGURATION 2 - Material Composition

Specifications

Primary Strand Stainless Steel AISI 440C (1.20\% C)

Central Core Wires Stainless Steel AISI 440C $(1.20 \%$ C)

Central Core's Core Stainless Steel AISI 440C (1.20\% C)

The Rope friction factor during stand still situation is given as

$$
f=m_{y}\left(\frac{1}{\sin \left(\frac{\gamma}{2}\right)}\right)
$$

where gamma $(\gamma)=$ groove angle $=30^{\circ}$.

Maximum possible pressure experienced by the wire rope is given by

$$
P_{\max }=\frac{12.5 \times 4 \times V_{s}}{1+V_{s}}
$$

where $P_{\max }=$ Max. specific pressure of the rope $\left[\mathrm{N} / \mathrm{mm}^{2}\right]$, $V_{s}=$ Rope speed of the traction sheave $[\mathrm{m} / \mathrm{s}]=1 \mathrm{~m} / \mathrm{s}$. 


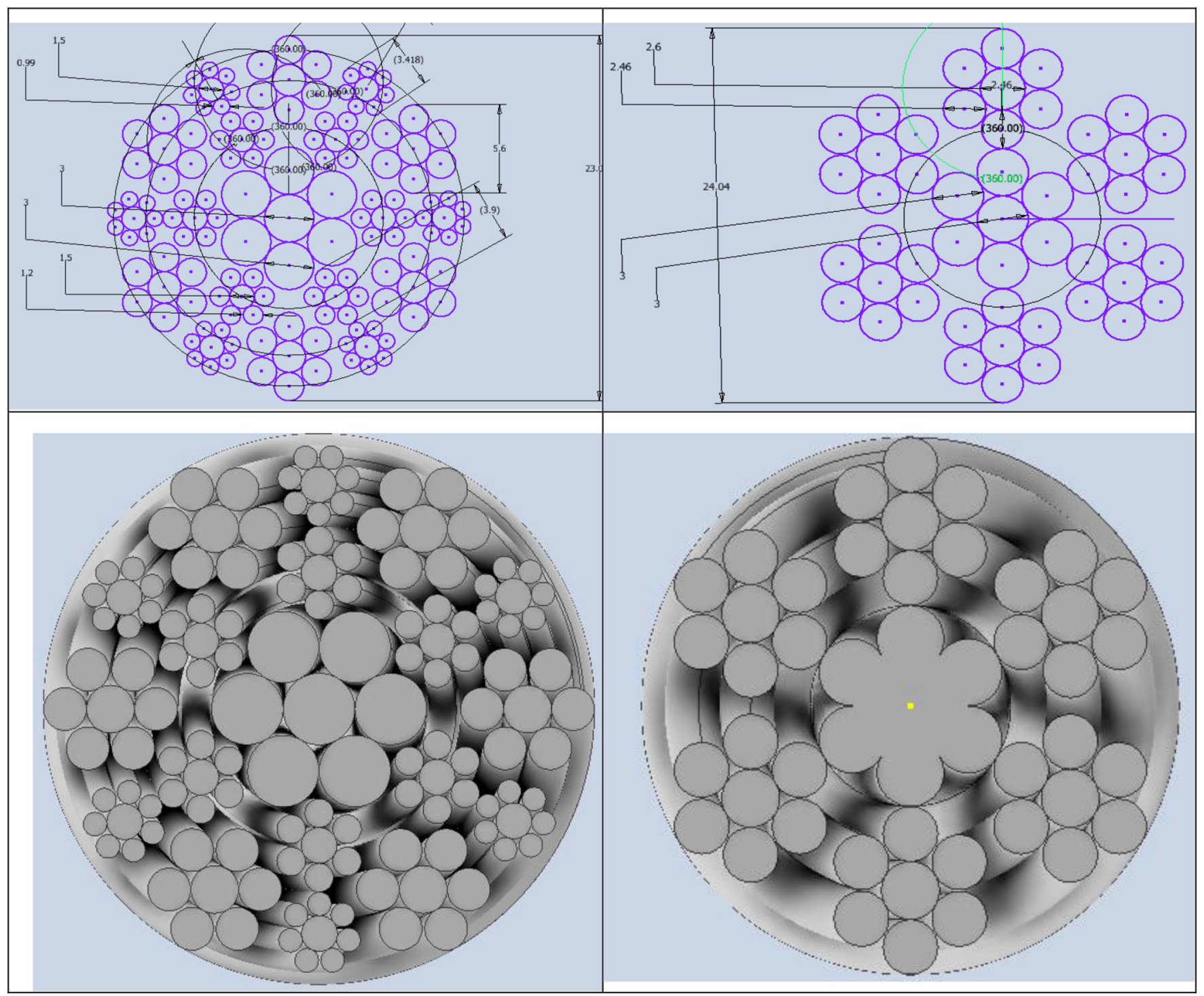

Fig. 2. Dimensions and front view of wire ropes considered (Configurations 1 and 2).

Actual specific pressure experienced by the wire rope is given as

$$
p=\frac{T}{\left(\frac{\left(N_{r} \times D_{r} \times D_{t}\right) \times 8 \times \cos \left(\frac{\beta}{2}\right)}{\pi-\beta-\sin \beta}\right)}
$$

where $p=$ Specific Pressure of the rope [MPa], $N_{r}=$ number of the ropes $=5, \quad D_{r}=$ rope diameter $[\mathrm{mm}]=$ $22 \mathrm{~mm}, D_{t}=$ diameter of traction sheave $[\mathrm{mm}]=400 \mathrm{~mm}$, $T=$ Static Rope force car side (Rated load bottom floor) $[\mathrm{N}]=36910, s=$ Rope Speed on Sheave $[\mathrm{m} / \mathrm{s}]=1 \mathrm{~m} / \mathrm{s}$, Gamma $(\gamma)=$ groove angle $=30^{\circ}$, beta $(\beta)=$ undercut angle $=105^{\circ}$.

\subsection{Checking for the sufficiency of the pulleys}

$K p=(D t / D p)$ where $K p=$ Ratio factor for difference in sheave and wire dia, $D_{t}=$ Dia. of Sheave $[\mathrm{mm}]=400 \mathrm{~mm}$, $D p=$ Avg. Dia. Of all the sheaves $[\mathrm{mm}] 400 / 5=80 \mathrm{~mm}$.

$N e q^{p}=(N p s+4 N p r) K p$ where $N=$ Number of pulleys, $N e q^{p}=$ Number of Drive pulleys, $N p s=$ No. of sheaves with eased bends $=6, N p r=$ No. of sheaves with negative bends $=0$.

Since the $K p$ value equals the Number of pulleys drives as calculated, the number of pulleys so assigned is appropriate.

The effective loads experienced by the wire rope is calculated using

$T=F \operatorname{car}($ operation $)=\frac{\left(m_{y}(\text { operation }) \times Q+P_{\max }\right) \times g}{r}$

where $m_{y}$ is the friction coefficient and $Q$ is the load. 


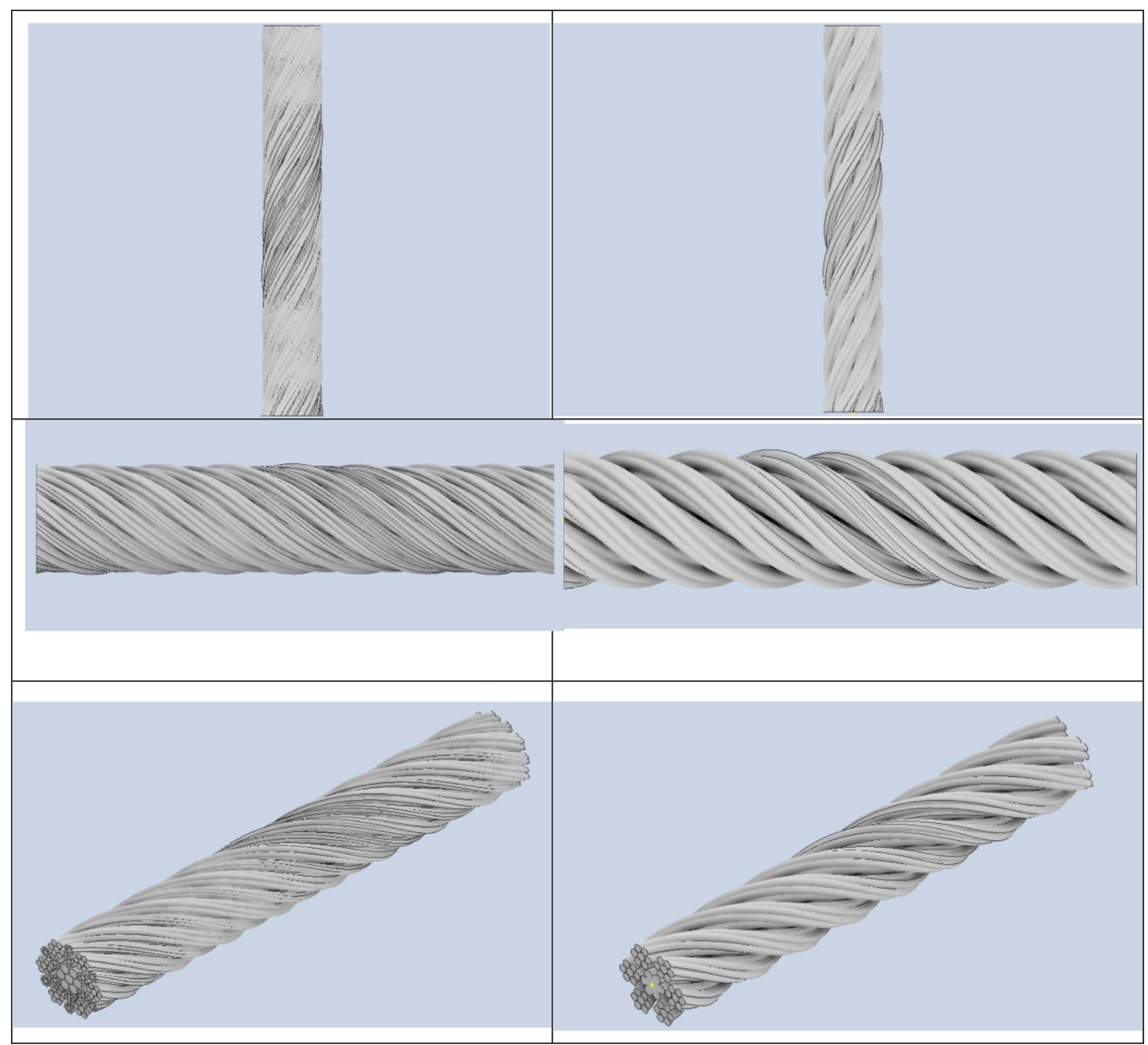

Fig. 3. Master view, right view, and isometric view of the wire rope (Configurations 1 and 2).

\subsection{Factor of safety}

Since normal breaking strength of Wire Rope $\mathrm{C} 1 \approx 212 \mathrm{KN}$ and for Wire Rope $\mathrm{C} 2$ of designed diameter $\approx 286 \mathrm{KN}$, and maximum static load considering a freight elevator is $45 \mathrm{kN}$; The Factor of safety is the ultimate normal breaking strength of rope to the maximum static load ratio. i.e.,

$$
\begin{aligned}
& \text { FOS }=\frac{\text { Normal Breaking Strenth }}{\text { Maximum Stactic Load }}=\frac{212000}{45000}=4.71 \\
& \text { FOS }=\frac{\text { Normal Breaking Strenth }}{\text { Maximum Stactic Load }}=\frac{286000}{45000}=6.35 .
\end{aligned}
$$

\section{Results and discussions}

\subsection{CAD model analysis}

The two-wire rope model is constructed, and these wire ropes were tested against static structural analysis by applying a load of $45 \mathrm{kN}$. Stress analysis have been conducted on both the models (Configurations 1 and 2). The corresponding dimensions and the views of configurations 1 and 2 is as shown in Figure 2 and Figure 3. The analysis is performed by taking a small cross section of the wire rope considering one end as fixed and negative load is applied on the other end in the opposite directions. The model of configurations 1 and 2 and the corresponding meshed model of configurations 1 and 2 is as shown in 


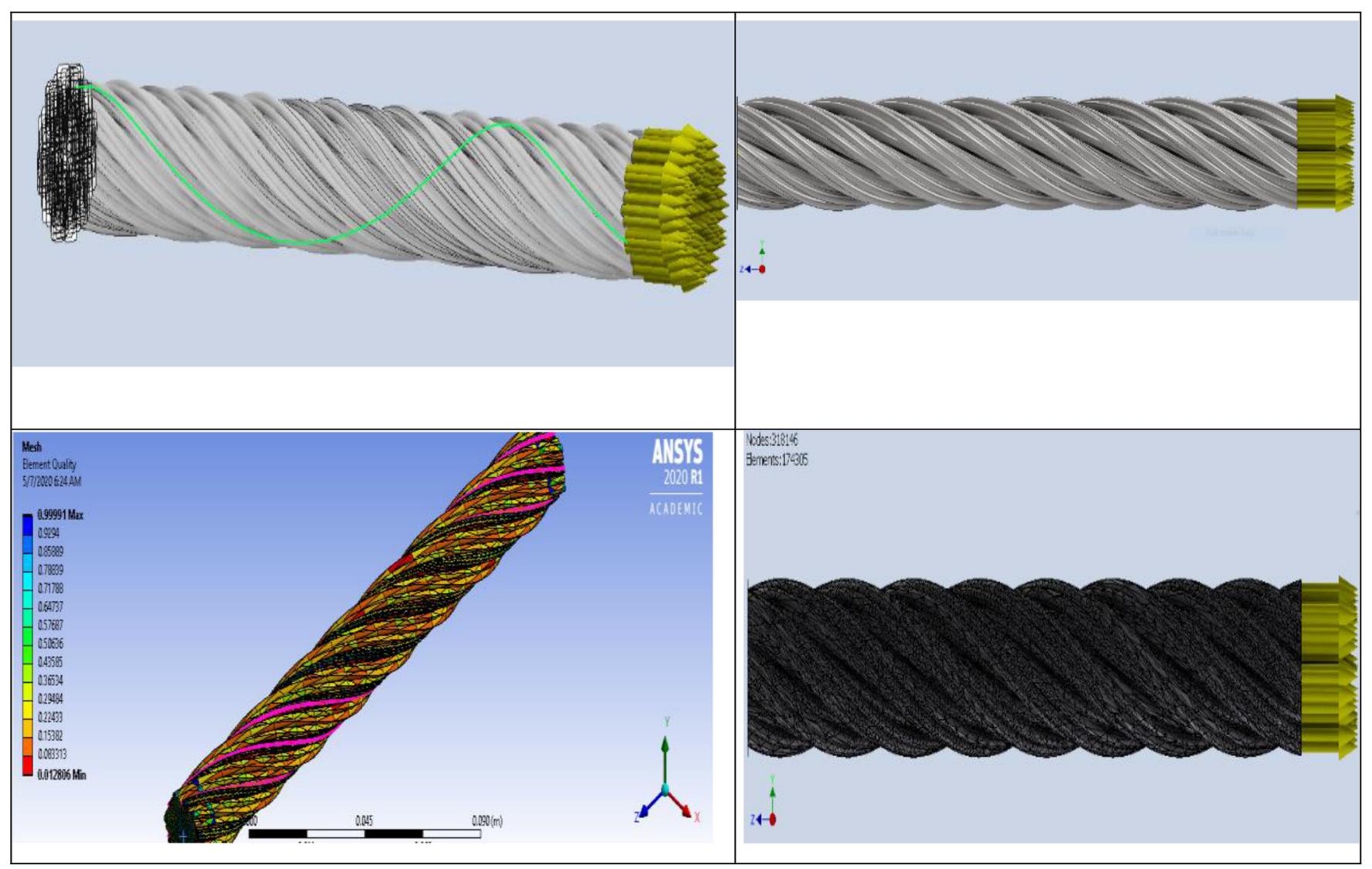

Fig. 4. Cad model and mesh model of configuration 1 and 2.

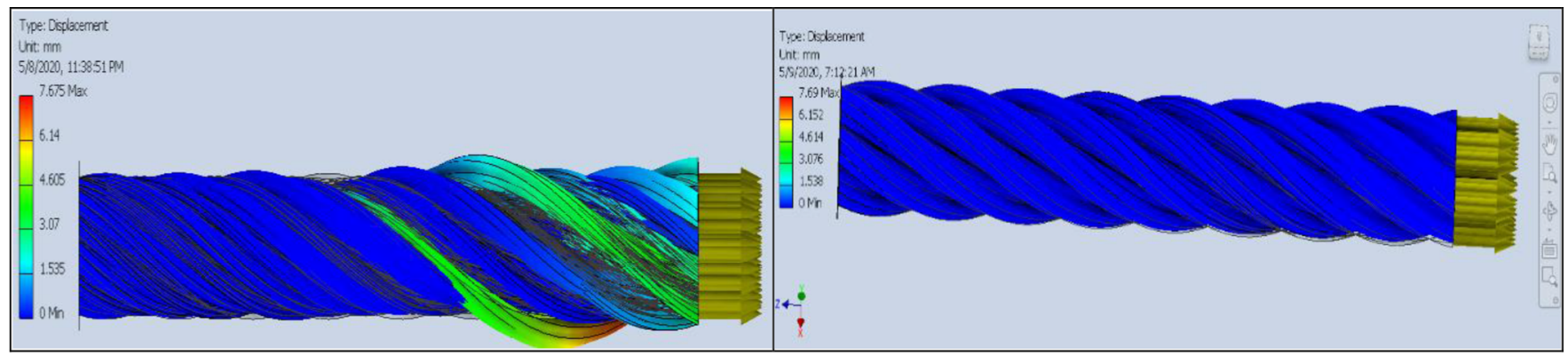

Fig. 5. Displacement diagrams of configuration 1 and 2 at a load of $45 \mathrm{kN}$.

Figure 4 and the number of nodes for the model meshing is 318166.

\subsection{Analysis results of wire ropes}

Figure 5 shows the displacement diagrams of wire ropes (configurations 1 and 2) for a load of $45 \mathrm{kN}$. From Figure $5 \mathrm{a}$ it is observed that wire rope is displaced in the low region of deformation, however, the far end of the wire rope shows individual strand displacement of up to $7.675 \mathrm{~mm}$ maximum. This wire rope is of the configuration $7 * 19$ which is considered unfamiliar and unconventional. From this it can be stated that with the usage of wire terminations or wire rope sling terminations the above deflections may be avoided which guaranty a sturdy and secure wire rope with high strength and high level of tolerance.

The wire rope configurations considered for the second case represents wire rope of $6^{*} 49$ design as compared to configurations 1 is as shown in Figure 5b. This wire rope 
Table 4. Wire Rope Physical Properties for GCS and Galvanized Steel (Analysis Values).

\begin{tabular}{lll}
\hline \multicolumn{1}{c}{ Physical Properties } \\
\hline Material & GCS (Galvanized carbon steel) & Steel, Galvanized \\
\hline Density & $1 \mathrm{~g} / \mathrm{cm}^{3}$ & $7.85 \mathrm{~g} / \mathrm{cm}^{3}$ \\
Mass & $0.0381284 \mathrm{~kg}$ & $0.299812 \mathrm{~kg}$ \\
Area & $99805 \mathrm{~mm}^{2}$ & $58189.6 \mathrm{~mm}^{2}$ \\
Volume & $38128.4 \mathrm{~mm}^{3}$ & $38192.7 \mathrm{~mm}^{3}$ \\
& $\mathrm{X}=0.0000000510449 \mathrm{~mm}$ & $\mathrm{X}=0.000000040191 \mathrm{~mm}$ \\
Center of Gravity & $\mathrm{Y}=0.0000000711695 \mathrm{~mm}$ & $\mathrm{Y}=0.000000122819 \mathrm{~mm}$ \\
& $\mathrm{Z}=-75 \mathrm{~mm}$ & $\mathrm{Z}=-75 \mathrm{~mm}$ \\
\hline
\end{tabular}

configurations have been analyzed using Auto desk inventor using stress component displacement analysis and the number of nodes considered is 318166 . This type of design is unconventional and never been constructed or analyzed for application. From this result it can be concluded that for a load of $45 \mathrm{kN}$, this wire rope has performed very well, and all the strand separation is intact which can be observed from Figure 5b. From this result it can be stated that the configuration 2 design is highly desirable in elevator lifting wire rope as it is having minimum strand separation and will guarantee maximum safety.

Table 4 shows the wire rope physical properties for GCS (Galvanized carbon steel) and galvanized steel considered for the analysis. From this table it is observed that mass of the wire rope made of GCS has $0.0381284 \mathrm{~kg}$ while the mass of the galvanized steel is $0.299812 \mathrm{~kg}$. From this table it is also observed that area of GCS is $99805 \mathrm{~mm}^{2}$ whereas the area of galvanized steel is $58189.6 \mathrm{~mm}^{2}$. The density as well as center of gravity of both these cases can also be observed in Table 4.

\section{Conclusions}

This paper discussed about the design and analysis of a wire rope used in elevator system. The analysis has been performed considering two configurations of wire rope considering GCS and Steel Galvanized. From the analysis the following conclusions have been drawn.

- The static structural analysis using ANSYS has been performed by considering the two wire strand configurations of wire ropes to increase the efficiency and life of the wire rope without compromising the safety of rope. - From this analysis it is observed that wire strand configuration 1 has shown internal strand to strand displacement and the factor of safety was less than 5 which is not recommended as per industry standards whereas, the strand configuration 2 has shown no internal displacement and has performed better as compared to configuration 1 and the factor of safety was higher as compared to the configuration 1 and is good design.

- The wire rope design using Autodesk inventor software and the analysis have been performed using Ansys. From this analysis it can be concluded that design of wire rope considered for the study increases the efficiency and life of the wire rope without compromising safety.

\section{References}

1. J.W. Phillips, G.A. Costello, Analysis of wire ropes with internal-wire-rope course, J. Appl. Mech. Trans. ASME 52, 510-516 (1985)

2. W.S. Utting, N. Jones, The response of wire rope strands to axial tensile loads - Part II. Comparison of experimental results and theoretical predictions, Int. J. Mech. Sci. 29, 621-636 (1987)

3. H. Mouradi, A. Barkany, A. EI Biyaali, Steel wire ropes failure analysis: experimental study, Eng. Failure Anal. 91, 235-242 (2018)

4. C. Yuanpei, M. Fanming, G. Xiansheng, Full contact analysis of wire rope strand subjected to varying loads based on semi-analytical method, Int. J. Solids Struct. 117, 51-66 (2017)

5. M. Giglio, A. Manes, Life prediction of a wire rope subjected to axial and bending loads, Eng. Failure Anal. 12, 549-568 (2005)

6. C. Erdonmez, C.E. Imrak, New approaches for model generations and analysis for wire rope, Int. Conf. Comput. Sci. Appl. 101-111 (2011)

7. C.R. Chaplin, Interactive fatigue in wire rope applications (University of Reading, 2008), 1-12

8. S.H. Kim, R.H. Bae, J.D. Kwon, Bending fatigue characteristics of wire rope, J. Mech. Sci. Technol. 26, 2107-2110 (2012)

9. H. Mouradi, A. Barkani, E.I. Biyaali, Investigation on the main degradation mechanisms of steel wire ropes: a literature review, J. Eng. Appl. Sci. 11, 1206-1217 (2016)

10. A. Barkani, A. Benali, M. Ghorba, M. Chergui, A. Choukir, Nondestructive evaluation methods of broken wire ropes of lifting, Int. J. Res. Rev. Mechatr. Des. Simul. 2, 126-136 (2012)

11. V.V. Sukhorukov, D.A. Slesarev, A.V. Vorontsov, Electromagnetic inspection and diagnostics of steel ropes: technology, effectiveness and problems, Mater. Evaluat. 72, 1019-1027 (2014)

12. J. Rostami, P.W. Tse, M. Yuan, Detection of broken wires in elevator wire ropes with ultrasonic guide waves and toneburst wavelet, Struct. Health Monitor. 19, 1-14 (2020)

13. Y. Zhang, L. Jing, W. Zhan, J. Tan, A sensor for broken wire detection of steel wire ropes based on magnetic concentrating principle, Sensors (Basel Switzerland) 19, 1-14 (2019) 
14. X. Shi, Y. Pan, X. Ma, Modelling and analysis of ropesheave interaction at traction interface, J. Appl. Mech. 84, 1-9 (2017)

15. S. Nabijoe, R.E. Hobbs, Frictional performance of wire and fibre ropes bent over sheaves, J. Strain Anal. 30, 45-57 (1995)
16. W. Vogel, Influences of lifetime of wire ropes in traction lifts, 5th symposium of the mechanics of slender structures, J. Phys. Conf. Ser. 721, 1-5 (2016)

17. L. Xi, Z. Juwei, S. Jingzhou, Quantitative nondestructive testing of broken wires for wire rope based on magnetic and infrared information, J. Sens. 2020, 1-14 (2020)

Cite this article as: Anil Babu Seelam, Mohammad Saif Jawed, Sachidananda Hassan Krishanmurthy, Design and analysis of elevator wire ropes, Int. J. Simul. Multidisci. Des. Optim. 12, 20 (2021) 